\section{Operaciones de montaje y reescritura como huellas del tiempo en "Diagonal Cero"}

Julia Cisneros *

Resumen: Se reflexionará sobre la temporalidad en la publicación Diagonal Cero (1962 a 1969), cuyo editor fue el artista platense Edgardo Antonio Vigo. Trabajaremos con el concepto de montaje como clave de la temporalidad, tanto en lo que respecta a la publicación Diagonal Cero como en los libros de reescrituras del artista. Proponemos examinar la proyección de esta revista en la Exposición Internacional de Novísima Poesía haciendo referencia al montaje de la misma. A partir de estas descripciones relevaremos las producciones como parte de una concepción sobre el tiempo que incluye la materialidad de la publicación y la estética de la participación.

Palabras clave: Edgardo Antonio Vigo - Diagonal Cero - Poesía Visual - Temporalidades.

[Resúmenes en francés, inglés y portugués en la página 50]

${ }^{(*)}$ Licenciada en Letras por la Universidad Nacional de Córdoba. Egresada de la Tecnicatura en Artes Visuales por la Universidad Provincial de Córdoba. Cursa la Maestría en Estética y Teoría del Arte en la Universidad Nacional de La Plata. Desde 2013 integra el equipo de investigación "Heterodoxias y Sincretismos en el Sistema Literario Argentino", dirigido por Dra. Cecilia Corona Martínez y Dra. Andrea Bocco (UNC). Participa desde 2015 como investigadora en el Centro de Arte Experimental Vigo.

\title{
Introducción
}

Diagonal Cero fue una publicación dirigida por el artista platense Edgardo Antonio Vigo. Desde su aparición (1962), la revista se centró en la difusión de la poesía, en principio tradicional y hacia 1965 de tipo experimental (Barisone, 2012, 2016, 2017; De Rueda, 2003; Davis, 2006, 2009; Gradowczyk, 2008; Perez Balbi, 2009, 2016). En este artículo, trabajaremos con el concepto de montaje como clave de la temporalidad, en lo que respecta a dicha publicación. Proponemos examinar la proyección de Diagonal Cero en la Exposición Internacional de Novísima Poesía (1969), haciendo referencia al modo en que se organizó el montaje para la muestra. A partir de estas descripciones analizaremos las producciones como parte de una concepción sobre el tiempo que incluye la materialidad de la publicación y la estética de la participación (Diagonal Cero No 23, 1967, p. 2). 
El propósito es abordar las temporalidades de estos objetos desde dos claves: por un lado, relevando las publicaciones literarias con las que dialoga Diagonal Cero, a partir de la observación del viraje del canon de lecturas que Vigo propone en la revista; por otro, focalizando en su práctica de reescritura. Concibiendo como antecedente a dicha publicación, en una segunda instancia, estudiaremos las tres secciones en las que se dividió la Exposición Internacional de Novísima Poesía '69 para estudiar el montaje, en tanto entrecruzamiento de actos que indican la convivencia de temporalidades heterogéneas (Didi-Huberman, 2015).

Dado que estos materiales forman parte del archivo del Centro de Arte Experimental Vigo, nos detendremos también en el proceso de digitalización, el cual facilita nuevas lecturas y sentidos de estas prácticas experimentales de la vanguardia argentina.

\section{Plataforma “Diagonal Cero": Diálogo y tensión}

Las revistas literarias se presentan como fuente para analizar el círculo de intereses cognoscitivos de una época, pero además revelan puntos de contacto y estrategias de vínculo en sus sistemas de legitimidades. En este apartado, relevaremos las revistas literarias platenses -específicamente aquellas contemporáneas a Diagonal Cero-, para examinar los modos en que esta publicación estableció lazos explícitos y rechazos. Para ello, hacemos una breve referencia al documento "Las revistas literarias argentinas 1893 a 1967" (1968), por el histórico Centro Editor de América Latina puesto que presenta una fuente insoslayable de datos que permiten acercarnos a las ediciones platenses que convivieron con la revista sobre la que nos interesa indagar.

En el prólogo, los compiladores Lafleur, Provenzano y Alonso argumentan sobre la selección de las publicaciones y definen el concepto de revista literaria como la "exteriorización de un grupo, conjunto o cenáculo de intelectuales que buscan a través de ellas la difusión de su mensaje, libres de objetivos comerciales y al margen del presupuesto oficial" (Lafleur Provenzano y Alonso, 1968, p. 9).

Respecto de la generación del '40, los investigadores destacan el aumento en la cantidad de ejemplares referidos a la literatura, en especial a la poesía, manifestando que:

En este momento de gran efervescencia juvenil que va trepando los escalones de la década del ' 40 y '50, cobra auge una forma de publicación distinta a las revistas: son los cuadernillos de poesía y prosa, hojas de poesía, cuadernos de literatura. De aparición periódica, son editados generalmente por una sola persona y, por supuesto, sin características de empresa editorial. (Lafleur Provenzano y Alonso, 1968, p. 188)

Sobre las revistas platenses distinguen a Teseo (1941), dirigida por Denis-Krause y quien también interviene en las Ediciones del Bosque, cuyas series dieron voz a autores tales como: Aurora Venturini, Maria Elena Walsh, Vicente Barbieri, entre otros. "En tantos años de su publicación, Teseo queda en la extensa galería de las revistas argentinas como una alta empresa de arte" (Lafleur Provenzano y Alonso, 1968, p. 209). 
Denis-Krause, en colaboración estrecha con Marcos Fingerit, fundará los cuadernillos conocidos como M. F (1942-1943). Las publicaciones Delfín (1944) y Unicornio (19481953) de Krause y Fingerit, "son muestras más de su incansable actividad de revistero. Las mismas, de excelencias tipográficas y la impecable diagramación, que siempre han distinguido sus realizaciones, hacen de ellas dos curiosas piezas para bibliófilos" (Lafleur Provenzano y Alonso, 1968, p. 210). Destacan la publicación Árbol del Centro de Estudiantes de Humanidades, editado en 1942 y Libertad Creadora (1943), dirigida por Alejandro Korn donde escriben Anderson Imbert, Ezequiel Martinez Estrada, Pedro Henriquez Ureña, entre otros.

En el capítulo "Los Últimos Años", las revistas platenses recopiladas son:

Buenos Aires (1961-1962), dirigida por Ataúlfo Pérez Aznar.

Cencerro (1958-1961), dirigida por Felipe Pérez Pollan.

Diagonal Cero (1962-1968), dirigida por Edgardo Antonio Vigo.

Edición (1951).

Espacios (1963-1964), dirigida por Mario Porro, José A. Jorajuria, Elba Ethel Alcaráz.

Letras (1951).

Lori Bilori (1955), dirigida por Eduardo Zapiola.

W. C. (1958), dirigida por E. A Vigo.

Remitido (1962-1963), dirigida por Angel Hector Azeves.

Sudestada (1952), dirigida por Hebert B Smith.

Vértice (1963), dirigida por Leonardo Simone.

Ahora bien, ¿cómo Diagonal Cero establece vinculación con las revistas contemporáneas? En su primer número se explícita: "Deseamos el canje con todas las publicaciones de tipo similar" (Diagonal Cero No 1, 1962). Debido a esto, en los números 3 y 4, hemos encontrado no solo referencias a publicaciones de la ciudad de La Plata como Teseo -dirigida por Krause-, sino ejemplares en su biblioteca personal del resto del país y con orientación surrealista como Cero (1964-1967), coordinada por Vicente Zito Lema, así como fascículos de A partir de Cero.

Dado que Vigo mantiene correspondencia con otros productores y editores, desde el $\mathrm{N}^{\circ}$ 7 se sugiere la adhesión a otras revistas. "Suscríbase a: Caballete, Espacios, La Voz en el Tiempo, Eco Contemporáneo, El Fantasma Flaco, Tiempo de Cine y Mediodía”. En la editorial del mismo número toma postura hacia una participación centrada en el reconocimiento de autores y artistas locales, enunciado que: "Diagonal Cero sin poner barreras a los testimonios nacionales y extranjeros de vital importancia para el progreso comunicativo, hará especial importancia en la transcripción de testimonios de nuestro acervo local: La Plata”. (Diagonal Cero N 7, 1963)

En concordancia con la afirmación sobre la importancia de visibilizar los testimonios locales, Diagonal Cero pone en circulación poemas del Grupo los Elefantes integrado por del editor platense Denis Krause y los artistas Pacheco, Pazos, Guinzburg, entre tantos otros. La obra: "Palabras colgadas ante los ojos", da muestra de ello. (Diagonal Cero N ${ }^{\circ}$ $5-6,1963)$ 
Si al comienzo decíamos que las revistas literarias son espacios donde se visibilizan tensiones y discursos de época, Vigo es categórico respecto a ello y a la orientación estética de las publicaciones locales. En su artículo: "Balance de la Plástica platense" afirma:

Las revistas: casi inexistentes, dan poca importancia a la plástica local, y siguen en su mayoría la línea escapista-europea, (puede ser producto de nuestra Universidad) perdiéndose en el análisis de los movimientos internacionales sin ninguna referencia a la plástica nacional o latinoamericana. Ejemplo la desaparecida o adormilada SIGLO XXI. (Diagonal Cero N 9-10, 1964, p. 3)

Consideramos que Vigo utiliza Diagonal Cero, para interactuar con sus colegas de manera polémica no solo con los valores que, según él, persiguen sus contemporáneos platenses sino también, en el modo de concebir la producción de estos objetos. En términos de Vigo, se debe trabajar por una estética participante (Diagonal Cero $\left.\mathrm{N}^{\circ} 23,1967\right)$, contrapuesta a una estética de la observación; en esta línea de concepción editorial, el procedimiento de montaje será la clave temporal y material con la que el autor interviene en su publicación disputando espacios de legitimidad para ofrecer otro tipo de materialidad y de lecturas. El procedimiento de montaje propuesto en las páginas de toda la serie de Diagonal Cero consolida la metáfora del tiempo, en tanto que a partir de la calidad y el formato que propone, el lector contemporáneo advierte las discusiones de ese tiempo histórico, sobre los modos de lectura y procedimientos de edición. Según Ana Bugnone (2014), esto se debe a la concepción de ensamble que corresponde a:

Montaje de trabajos de diversos artistas que un editor se encarga se aunar, similar al libro de artista y cuyas estrategias comunicativas se separan de las limitaciones del mundo editorial (...). Si bien en las revistas ensambladas el contenido fundamentalmente tiende a ser visual, Vigo propuso también la permanencia de textos propios y de otros autores. (Bugnone, 2014, p. 6)

El canon que propone Diagonal Cero se expone no solo desde los postulados teóricos sino también desde la acción concreta de la publicación. Irrumpe y discute con el formato tradicional de la revista ensayando un tipo de diseño donde se modifica el tiempo de lectura y el continente material de la misma. Desde esta perspectiva, el montaje es una aspecto sustancial para la creación; esta práctica que ha sido estimada por los estudios de vanguardia (Bürguer, 1987) como un procedimiento técnico que destruye la concepción de obra orgánica, permite que cada parte -que conforma el todo-, posibilite la producción de una aparente unidad emancipardora, en términos de Bürguer (1987, p. 113). Este principio impacta en la recepción de la obra, puesto que "la atención del receptor deja de dirigirse hacia un sentido de la obra que se alcanza por la lectura de las partes, por el contrario, debe lograrlo a partir del principio constructivo" (Bürguer, 1987, p. 115). Por su parte, DidiHuberman (2008) analizando el teatro épico de Brecht, señala que el montaje se asocia a un ordenamiento de temporalidades heterogéneas donde, 
No se muestra, no se expone más que disponiendo, no las cosas mismas (...). Sino sus diferencias, sus choques mutuos, sus confrontaciones, sus conflictos (...). Esto es el montaje: no se muestra más que desmembrando, no se dispone más que disponiendo primero. No se muestra más que mostrando la aberturas que agitan a cada sujeto frente a los demás. (Didi-Huberman, 2008, p. 97)

Diagonal Cero establece el canje con publicaciones similares pero expresa un alejamiento de las revistas platenses de su contemporaneidad, puesto que éstas no darían importancia al acervo local y mantendrían estructuras vinculadas a las formas de lectura y escritura de la poesía tradicional, signadas por una estética de la observación. Como productor y editor, Vigo expone mediante el montaje, la convivencia de temporalidades en documentos de autores platenses junto a teóricos y artistas extranjeros. Así, su enciclopedia de lecturas se vincula no solo con publicaciones de su geografía próxima sino con revistas tales como: Les Leters, Phantomas, Los huevos de Plata, Approches 3, Doc(k)s, que, entre otras obras de divulgación, son insumo para las transformaciones que se generan en Diagonal Cero. Estos textos exponen un corrimiento de referencias teóricas que confrontan con la estructura analítico-discursiva del poema tradicional. Como señala Magdalena Pérez Balbi (2008), "analizando el devenir de la revista, podemos observar que la reflexión sobre la palabra y el rol de la literatura y el arte, se inclina progresivamente hacia soluciones plástico-visuales y da cuenta de una crisis de ciertas convenciones literarias". (Pérez Balbi, 2008, p. 19)

En virtud de la cita, las modificaciones teóricas y la implicancia de la materialidad en Diagonal Cero plasman las tensiones con el universo de relaciones dejando expuesta la heterogeneidad de temporalidades, tanto con la estética como con los postulados planteados de su época. Siguiendo esta línea, interesa indagar a continuación, cómo opera el tiempo en las lecturas que Vigo consume y difunde. Las formas en que Vigo selecciona un canon de autores para su publicación mediante las prácticas de reescritura, que además incidirá en las decisiones montaje para la organización de la Exposición Internacional de Novísima Poesía '69.

\section{Casos de reescritura sobre Poesía Visual}

Los textos de reescrituras expuestos en Diagonal Cero nos interpelan: ¿Por qué volver a escribir algo que ya existe? Ejemplares únicos mecanografiados y re-diagramados por el artista, libros completos o bien partes de artículos y textos, muchos de ellos traducidos del francés por su esposa Elena Comas. Las temáticas fundamentales que abordan corresponden a vanguardias históricas, historietas y poesía visual. Estas reescrituras dan cuenta de un tiempo de lectura en el que opera tanto la apropiación como la reformulación y difusión de estos materiales.

La práctica de la reescritura en la obra de Vigo se configura como una incursión temprana en el mundo de la edición donde el procedimiento de montaje posibilita observar el fluir del tiempo, en función de los cambios del artista sobre la concepción de la poesía. Si, como afirmamos en páginas precedentes, el montaje facilita la convivencia de tiempos heterogéneos (Didi-Huberman, 2015), el diseño organizativo que exponen estos libros posibilitan 
generar una diversa disposición del material preexistente produciendo un nuevo ejemplar. Estas reescrituras se corresponden con la práctica de montaje, dado que en ellas conviven: un catálogo seleccionado por Vigo -fragmento de textos o textos completos-, un diseño de libro -transcripción mecanografiada y encuadernación artesanal-, imágenes -anexadas o producidas por Vigo-, y un diálogo con la edición original. Los libros de reescritura de Vigo son obras que nos brindan conocimiento sobre tendencias artísticas, además de postular la diferenciación con una tradición poética desde una mirada crítica para modificar su estructura tanto en su formato -elaboración de nuevos ejemplares-, como en la circulación de estos textos en un nuevo contexto. Pero: ¿Cómo incide la acción de reescribir sobre la materialidad de Diagonal Cero? Sostenemos que este montaje corresponde, por un lado, al tiempo de la reescritura y por otro, al tiempo en el que esos textos son re-publicados en la revista. En el caso que analizamos a continuación, el manifiesto de Garnier, ha sido publicado inicialmente el 30 de septiembre de 1962 por la revista Les Leters haciendo sido traducido, reescrito y vuelto a publicar en Diagonal Cero No 23 (1967). Así, mientras en 1962 Diagonal Cero exponía referentes de las vanguardias históricas junto a poetas platenses, cinco años después, publicaría el manifiesto para una poesía visual, acercándose a los postulados que sustentan la Exposición Internacional de Novísima Poesía '69.

Las fechas en las que fueron elaborados estos ejemplares comprenden desde mediados de la década del ' 50 -luego de su viaje a Europa- hasta comienzos de la década del '70. El corrimiento de las referencias en las lecturas de Vigo, europeas y, particularmente, francesas primero, estadounidenses y latinoamericanas después, está acompañado de una fragmentación en los textos que se manifiesta en los tomos de reescrituras de libros completos y los tomos de reescrituras de artículos. En los segundos se transcriben mayormente artículos de periódicos, suplementos culturales y revistas. Los dos textos que examinaremos a continuación corresponden a dos cronologías distintas en la trayectoria de Vigo como lector y editor, la primera vinculada a las vanguardias históricas, la segunda a una Diagonal Cero consolidada.

Figura 1. Francis Picabia, "Aforismos" (Diagonal Cero $\left.N^{\circ} 2,1962\right)$.

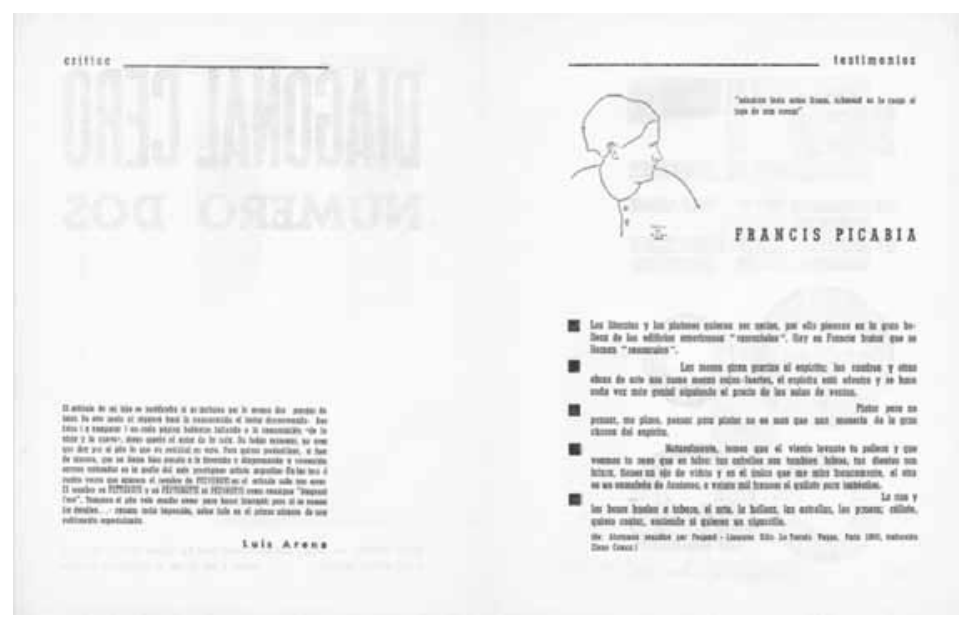

Cuaderno 75 | Centro de Estudios en Diseño y Comunicación (2019). pp 37-50 ISSN 1668-0227 
En el No 2 (1962) de la revista, encontramos de Francis Picabia una selección extraída de "Aforismos reunidos por Poupard". Se especifica que pertenece a la edición Lieussou, Le Terrain Vague, (París, 1960), con traducción de Elena Comas. En el mismo número también figura una "Pequeña Antología de Poetas Jóvenes": Barragan Lid, Raúl Fortín y Omar Gancedo, (1962) y extractos de "Poemas Radioactivos", del grupo Los Elefantes (1962). Vemos aquí la combinación de referentes nacionales y extranjeros, temporalidades y perspectivas que se exponen en los inicios en la publicación: vanguardias históricas junto a poemas y obras de jóvenes artistas platenses. Conforme Vigo establece comunicación con otras publicaciones y documentos teóricos se produce el viraje de Diagonal Cero, sin embargo, veremos como las vanguardias históricas continuarán siendo insumo.

Como señalamos al comienzo de este artículo, muchos textos teóricos sobre poesía experimental anunciados en Diagonal Cero pertenecen a extractos de revistas extranjeras y nacionales que Vigo consume, los cuales han sido reescritos y vueltos a publicar en las páginas de Diagonal Cero. Las reescrituras sobre las que el artista trabaja se configuran como un espacio de reflexión acerca de la poesía y los movimientos estéticos; tal es así que partir del $\mathrm{N}^{\circ} 20$, se modifica el perfil de la revista. Nos detendremos en el $\mathrm{N}^{\circ} 23$ donde se difunde el "Manifiesto para una nueva poesía Visual y Fónica", de Piere Garnier, reescrita de la revista Les Letters $\mathrm{N}^{\circ} 29$ (1962). Acompañan esta publicación tres obras de la poeta visual italiana Mirella Bentivoglio, junto a "Composición poema matemático", de Vigo y poemas de Jorge de Lujan Gutiérrez, Carlos Raúl Guinzburg y Luis Pazos.

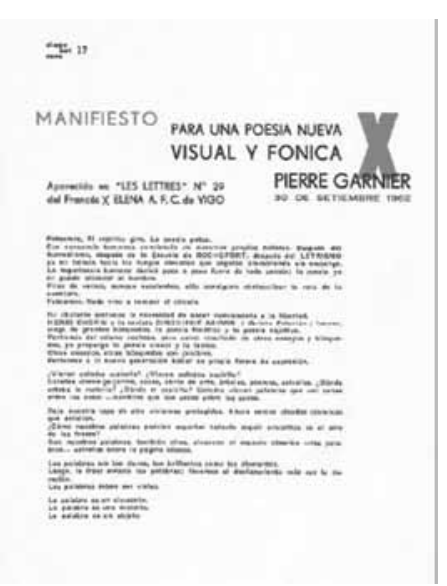

Figura 2.

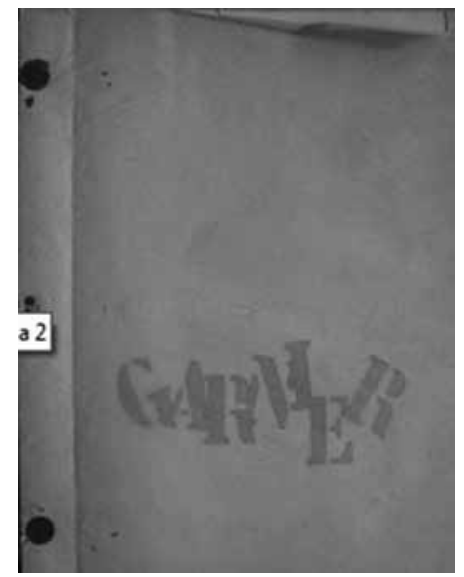

Figura 3.
Figura 2. Tapa "Garnier” (Reescritura de Vigo, 1967). Archivo CAEV. Figura 3. "Manifiesto para una nueva poesía Visual y Fónica”. (Garnier, 1967, en Diagonal Cero $\left.\mathrm{N}^{\circ} 23\right)$.

El género manifiesto, explotado por las vanguardias históricas y retomado por Garnier, destaca la existencia de un "nosotros"; junto al intento por asir determinados valores como definir y actuar conforme a una postura (Cippolini, 2003). El "Manifiesto para una nueva poesía visual y fónica" postula: 
Las palabras deben ser vistas.

La palabra es un elemento,

La palabra es una materia,

La palabra es un objeto.

(Garnier, 1967, Diagonal Cero Nº 26).

Si en los inicios de Diagonal Cero, Vigo publica aforismos de Picabia junto a las escrituras del grupo los Elefantes; con el correr del tiempo, encontramos una coherencia interna entre lo que se dice sobre la palabra, en tanto objeto, en términos de Garnier (1967) y las experiencias plásticas que circulan en la revista. Consideramos que el corrimiento en el perfil de la revista se corresponde, en gran parte, con las transformaciones en las lecturas que consume su editor plasmadas en los libros de reescrituras. De cualquier forma, no se eliminan los antecedentes de las vanguardias históricas, éstas se integran en la narración de un origen. La publicación Diagonal Cero vinculada a los libros de reescrituras permite un acercamiento a las modificaciones tanto materiales como teóricas que operan en la temporalidad publicación.

Por último reflexionaremos sobre el lugar del lector en Diagonal Cero como modo de establecer una diferenciación con las publicaciones contemporáneas platenses: "La poesía visual y la poesía fónica cambian la destinación del lector. Este hasta entonces era preciso. El poema se cerraba sobre él. La poesía nueva exige su colaboración” (Garnier, 1967, Diagonal Cero $\mathrm{N}^{\circ} 23$ ). El tiempo de lectura que ensaya esta revista discute con el formato de revista tradicional puesto que su manipulación implica otro cuerpo y otras claves de leer, respecto de la estructura analítico-discursiva del poema tradicional, aquella estética de la observación de la que hablaba Vigo (1967). En este sentido, los libros de reescrituras no son solo un ejercicio de transcripción de textos escritos en el pasado hacia el presente sino experiencia de diseño de la palabra hacia el futuro.

Nos detendremos a continuación en las decisiones de montaje, en tanto manifestación de temporalidades (Didi-Huberman 2015), de la Exposición Internacional de Novísima Poesía '69.

\section{Exposición Internacional de Novísima Poesía'69}

La poesía neo concreta brasileña ingresa a Diagonal Cero, a partir del $N^{\circ} 22$ (1967) donde Vigo traduce y publica "Poesía Concreta Brasilera" de Haroldo de Campos y el poema concreto de Augusto de Campos "Sem un numero". Así mismo, en el No 26 (1968) encontramos de Decio Pignatari, "Hombre" y el poema de Alvaro de Sá "Poema de 12x9". Haroldo De Campos, sugiere a Jorge Romero Brest la coordinación de esta muestra a cargo de Edgardo Antonio Vigo. En la epístola, De Campos señala:

En Argentina, el coordinador de la muestra podría ser Edgardo Antonio Vigo, coordinador de Diagonal Cero que está ya en contacto con los poetas visuales de todo el mundo y empieza a introducir el movimiento en la Argentina (Carta de Haroldo De Campos a Romero Brest, 1967, Archivo Di Tella). 
La exposición reunió más de 150 obras realizadas por 132 artistas de 15 países y tuvo lugar entre el 18 de marzo y el 13 de abril de 1969, en el Centro de Artes Visuales del Instituto Torcuato Di Tella. El montaje fue diseñado en tres secciones, tal como quedó de manifiesto en el catálogo de la exposición. En la primera se mostraron revistas, catálogos y libros-objeto; en la segunda sección, poesía visual impresa y objetos; y la tercera, audiciones de poesía fónica. Las operaciones de montaje que Vigo organiza no son ajenas a sus preocupaciones por la materialidad de la palabra y la participación del espectador. Los cambios en sus postulados teóricos - plasmado en los libros de reescrituras y en Diagonal Cero-, se materializa en esta muestra como un alejamiento de los modos de disposición, respecto a las temporalidades que implica una exhibición tradicional.

Primera Sección: Orientado a ofrecer un panorama general de los estudios y experiencias sobre poesía visual en libros, catálogos y revistas. Las consideraciones teóricas que hemos relevado en el manifiesto de Garnier (1967), vuelven a resonar en las reflexiones sobre la muestra puesto que en la Exposición de Novísima Poesía '69 este argumento se exponen y se leen. Los cruces temporales y genealogías que inventa esta exposición se presentan, por ejemplo, en la sección de libros argentinos, donde conviven de Oliverio Girondo: "Veinte Poemas para ser leídos en el tranvía" (1922) “Calcomanias” (1925) y "Espantapájaros" (1932), junto a creaciones de los platenses Lujan Gutiérrez, Pazos, Vigo y Ginzburg. Sin embargo no aparecen, por ejemplo, las grafías plastiútiles de Xul Solar.

El corrimiento que produce la operación de este evidenciar la teoría para ofrecer al espectador/lector herramientas de lectura y genealogías temporales es una forma de incluirlo, informarlo y formarlo en estas prácticas experimentales. Si en el manifiesto de Garnier (1967), se indicaba que la poesía nueva exige la colaboración del espectador, Vigo sugiere que el artista debe propiciar espacios e instrumentos para esas lecturas, con el fin de que sean "programadores" (Vigo, 1969, p. 8); pero no solo eso, deben ser re-creadores atentos a la estética de la participación (Diagonal Cero No 23, 1967).

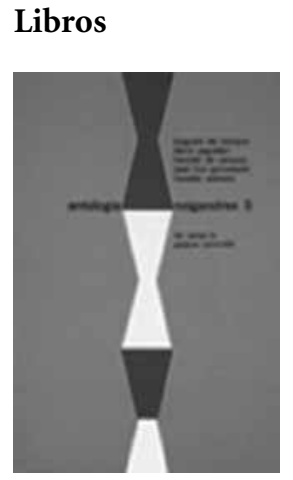

Figura 4.

\section{Catálogos}

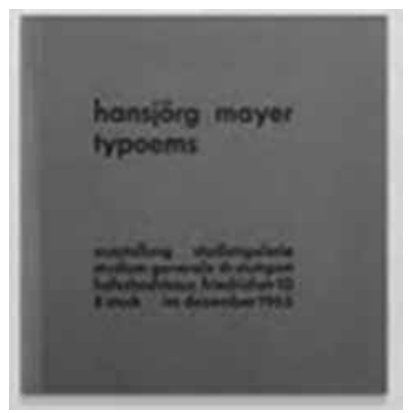

Figura 5.

\section{Revistas}

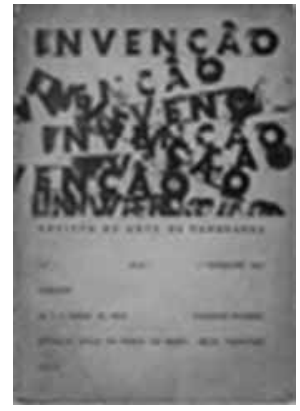

Figura 6.

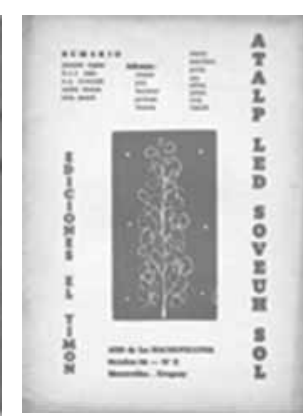

Figura 7.

Figura 4. "Antología Noingrandes” (Grupo Noigrandes, 1962). Figura 5. “Typoems” (Hansjórg Mayer, 1965). Figura 6. "Invenção" (s/r, 1962). Figura 7. "Los huevos del Plata” (s/r, 1966). 
Vigo realiza fichas mecanografiadas de más de doscientos ejemplares entre libros, catálogos y revistas. En el Catálogo de la muestra se explicita:

Cada volumen es acompañado por una ficha bibliográfica conteniendo datos editoriales, pequeño comentario de las características fundamentales de la publicación, artículos que se incluyen en el texto y lista de las reproducciones de los artistas incluidos (Vigo, 1969, p. 10).

En la década del '60, estas fichas servirían para el reconocimiento y control de cada ejemplar. La breve descripción y diseño de estas tarjetas pueden vincularse con la práctica de reescritura que abordamos en el apartado anterior. En ellas Vigo describe y diseña el contenido de ese libro/revista o catálogo, respetando sus datos de edición pero evocándolo de manera personal, en una suerte de reescritura. En la actualidad, la versión digital de las mismas, las transforma en piezas de un rompecabezas que convergen en un tiempo presente entrecruzando el pasado, en tanto material creado para ser expuesto, y futuro como documentación a intervenir. Si, como señala Boris Groys (2014), cada acto de documentación y archivo supone un criterio de ordenamiento en relación al contenido, en este caso la diferencia entre aquel fichaje y el actual no solo radica en las tecnologías, allá la máquina de escribir y el soporte papel y aquí la web, sino también en las categorías de ordenamiento temporal y sus implicancias.

Figura 8. Fichas elaboradas por E. A. Vigo.

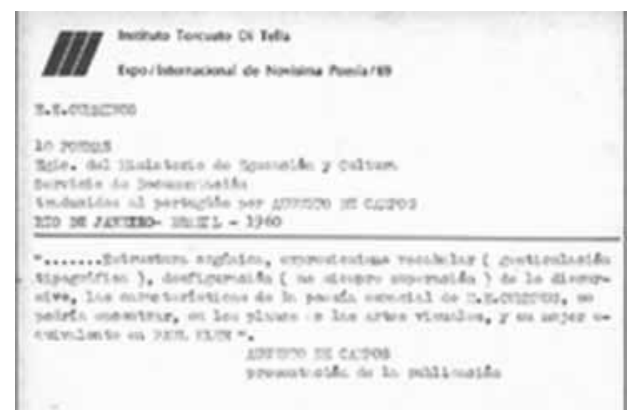

Segunda Sección: Referida a poesía visual impresa y objetos. Vigo confeccionó soportes rígidos de 35 x 50 con cuatro ojales en las esquinas para exponer las obras y unificar el formato de los afiches. La digitalización y conservación de estos materiales resulta dificultosa y a casi 60 años de la exposición, por las huellas que representan el paso del tiempo en el tipo de pegamento utilizado, la decoloración y los daños en el papel. Junto al equipo del Centro de Arte Experimental Vigo, hemos decidido realizar fichas digitales por países donde ordenamos el material perteneciente a los autores respetando el ordenamiento que Vigo le otorga en el catálogo de la muestra. Muchos de los poetas visuales que exponen en esta sección han transitado por las páginas de Diagonal Cero, como los casos de: Mirella Bentivoglio (1968), Timm Ulrich (1968), Eugen Gombringer (1968), Luiggi Ferro (1968), entre otros. Este hecho da cuenta de los diálogos y proyecciones temporales que se presentan entre la publicación y la muestra. 
Se conservan fotografías de esta sección de la muestra en general y de las intervenciones tri-dimensionales -sobre las cuales Vigo reflexionara en su ensayo "De la Poesía/ Proceso a la poesía para i/o a realizar” (1969)-, pero no las obras originales de la exposición.

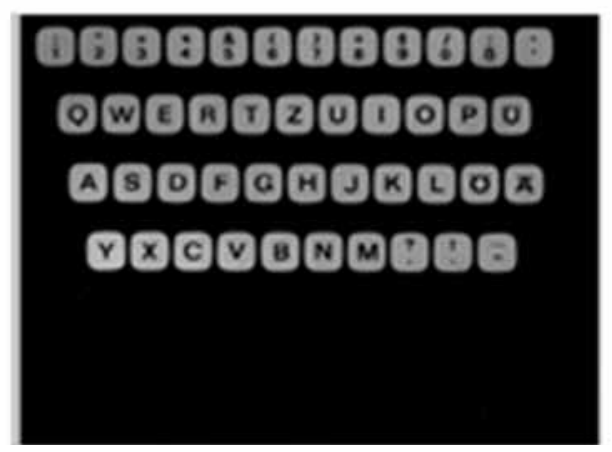

Figura 9. S/t (Timm

Ulrich, 1969).

Tercera Sección: Dedicada a la poesía fonética. En el texto que antecede al programa de la Exposición Internacional de Novísima Poesía '69, "A manera de introducción a los Poemas Sessions" dice:

El panorama comprende desde los históricos poemas fónicos, provenientes de las composiciones tipo collage y de carácter visual (...). Hasta el aprovechamiento de las reverberaciones, ecos, superposiciones de texto y voces, destrucción del registro natural por medios electrónicos, pasando por la poesía líquida, también escucharán los poemas pornográficos de John Giorgo quien ironiza al decirlos el tono de la oración colectiva en templo religioso (E. A. Vigo, en "A manera de introducción a los Poemas Sessions”, s/f, Colección Archivo Di Tella).

En esta genealogía, también dialogan vanguardias históricas y obras de su contemporaneidad. Resulta interesante que, en la carta enviada por Haroldo De Campos a Romero Brest, se indican como referentes para la exposición, poetas del campo de las experiencias visuales como Mathias Goeritz, Jasia Reichardt, Max Bense, y el Grupo Noigandres, sin hacer mención a la posible inclusión de poetas fónicos. Vigo incluye en la muestra a Raul Housmann con "Cinco poemas dadaístas", a Henri Chopin con "Audiopoema”, Bob Cobbing y Dick Higgins con "Alienación”, entre otros. En relación con la circulación de estas creaciones y el modo en que llegan a Vigo, se especifica en el programa de los Poema Session que fueron extraídos de la revista Disco OU, de H. Chopin, también presente en la biblioteca de Vigo.

En el desarrollo de las tres secciones que compusieron la Exposición Internacional de Novísima Poesía, hemos relevado el peso que adquiere la experimentación con el lenguaje a partir de decisiones sobre un espacio/tiempo, las maneras en que Diagonal Cero, como plataforma de poesía experimental, es un antecedente para el análisis del montaje de la misma. 
Las obras seleccionadas representan un acercamiento al público argentino de expresiones poco reconocidas dentro del ámbito artístico por su carácter liminar. Este carácter liminar, tensión que Vigo capitaliza, contempla la posibilidad de temporalidades de lectura y genealogías. Sobre la primera, el antecedente corresponde a Diagonal Cero donde el espectador es un hacedor del desmembramiento de la lectura; lo mismo ocurre con las decisiones de montaje para la Exposición Internacional de Novísima Poesía '69, el contacto directo del espectador con la materialidad y recorrido en los formatos es una manera de mostrar las aberturas que agitan tanto lecturas como sentidos. Respecto de las genealogías, se visibiliza en la muestra la herencia de las vanguardias históricas en los cruces temporales que inventa la Exposición Internacional de Novísima Poesía: Martinfierismo y Diagonal Cero, históricos poemas fónicos tipo collage y destrucción del registro natural por medios electrónicos.

El lugar preminente que ocupan las revistas y publicaciones con las que Vigo toma contacto, vuelven a ser el punto de inflexión en relación a las modificaciones que propone respecto del montaje como clave del tiempo. El viraje en las referencias teóricas plasmado en la publicación, gracias al trabajo con las reescrituras y la búsqueda de referentes teóricos, se materializa en la Exposición Internacional de Novísima Poesía como un alejamiento de los modos de presentación respecto de la exposición tradicional.

\section{Consideraciones finales}

En el recorrido propuesto para analizar el montaje como clave del tiempo en Diagonal Cero para observar el campo discursivo en el cuál se inserta esta publicación mediante los diálogos y tensiones que Vigo establece con las revistas de su contemporaneidad y antecedentes sobre los que se asientan los marcos históricos que propone. Analizamos también el modo en que la materialidad de Diagonal Cero ensaya cruces temporales, a través del procedimiento de montaje.

Interesó indagar la acción del tiempo en dos de las reescrituras que Vigo decidió publicar, considerando que ambas son hitos en la modificación del perfil editorial. Aquí intentamos dar cuenta de los cruces temporales mediante dos reescrituras que el artista selecciona para su difusión en la revista y la importancia que cobra este material teórico en su producción. Hicimos referencia a la transformación que opera en la producción de Vigo el viraje en sus lecturas, vinculadas con textos y obras publicadas nacionales y extranjeras. Finalmente trabajamos con los elementos que compusieron la muestra organizada por el artista en el Instituto Di Tella, los cruces entre Diagonal Cero y la poesía brasileña, así como las secciones en las que se organizó. La acción del tiempo aquí abordada desde el montaje, en relación a los modos de lectura, las genealogías y el aporte de los materiales teóricos.

En la actualidad, el objetivo de reconstruir la Exposición Internacional de Novísima Poesía '69 es doble: por un lado pretende lograr una facilidad para que investigadores interesados en el tema puedan acceder a este material desde el sitio web del Centro de Arte Experimental Vigo y por otro, para garantizar su conservación. Esta acción se constituye como un desafío respecto del ordenamiento y la decisión sobre categorías para su digitalización como también, sobre el flujo del tiempo que esta experiencia y la de los potenciales lectores conlleva. 


\section{Notas}

1. Remitimos a la Tesis Doctoral de Berenice Gustavino (2014): La escritura sobre arte en Argentina en los años sesenta. La crisis de las referencias extranjeras y la extensión de la perspectiva latinoamericana. FBA, UNLP.

2. Dentro de la publicación, el autor no es el único referente teórico de la poesía experimental. Figuran textos de Julien Blaine (DC $\left.\mathrm{N}^{\circ} 21,1967\right)$, Jean F. Bory (DC $\left.\mathrm{N}^{\circ} 21,1921\right)$, Henri Chopin (DC N $\left.{ }^{\circ} 24,1928\right)$, Mike Weaber (DC No 22, 1967).

3. En la biblioteca personal de Haroldo de Campos constan las siguientes publicaciones de E. A. Vigo: Vigo, Edgardo Antonio. "Edgardo Antonio Vigo Y Sus Cosas". São Paulo, 1996. /Vigo, Edgardo Antonio. "Poème Mathémathique Baroque”. Paris, Contexte. (1967) /Diagonal Cero. № 1 Al 4. La Plata, Buenos Aires, 1962. /Catálogo Movimiento Diagonal Cero. La Plata, Buenos Aires, 1967.

4. Se agradece el material facilitado por la Biblioteca Di Tella para la realización de esta publicación.

5. Dicha documentación puede verse en: www.caev.com

6. El Centro de Arte Experimental Edgardo Antonio Vigo, dirigido por Ana Maria Gualtieri y Mariana Santamaría, tiene como propósito, entre otros, la custodia, exposición y organización en archivos de los documentos del artista.

\section{Referencia Bibliográfica}

Barisone, O. (2012). Vigo y la Expo Internacional Novísima Poesía/69 (CAV-ITDT, 1969) como materialización del intercambio. Posibilidades del concretismo. Actas VIII Congreso Internacional de Teoría y Crítica Literaria Orbis Tertius. Facultad de Humanidades y Ciencias de la Educación Universidad Nacional de La Plata.

Bugnone, A. (2014). La revista Hexágono '71: 1971-1975 La Plata, Buenos Aires, Argentina. Biblioteca Orbis Tertius. Universidad Nacional de La Plata; Centro de Arte Experimental Vigo.

Bürguer, P. [1987] (2010). Teoría de la Vanguardia. Buenos Aires, Argentina. Ed. Las Cuarenta. Cipollini R. (2003). Manifiestos Argentinos. Buenos Aires, Argentina. Ed: Adriana Hidalgo. Didi-Huberman G. (2008). Cuando las imágenes toman posición, Madrid. Ed. Machado Libros.

Didi-Huberman G. (2015). Ante el Tiempo. Historia del Arte y anacronismo de las imágenes. Buenos Aires, Argentina. Ed: Adriana Hidalgo.

Groys, B. (2014). Volverse Público. Buenos Aires. Ed. Caja Negra.

Gustavino, B. (2012). Relevamiento de Libros artesanales de Vigo. Manuscrito que forma parte del Centro de Arte Experimental Vigo y que aún no ha sido publicado.

Pérez, Balbi M. (2008). Movimiento Diagonal Cero: Poesía Experimental Desde La Plata (1966-1969) Recuperado de: http://sedici.unlp.edu.ar/handle/10915/46011.

Lafleur H., Provenzano S. y Alonso F. (1968). Las revistas literarias argentinas. Buenos Aires, Argentina. Centro Editor de America Latina. Vigo E. A. Diagonal Cero (1962- 1968). Archivo Centro de Arte Experimental Vigo. 


\section{Archivos consultados}

Archivo Centro de Arte Experimental Vigo.

Archivo Instituto Di Tella, Universidad Torcuato Di Tella.

Résumé : Il s'agira dans cet article de se pencher sur la temporalité à l'œuvre dans la publication Diagonal Cero (1962-1969) éditée par l'artiste platense Edgardo Antonio Vigo. Nous travaillerons avec le concept de montage comme clé pour aborder cette temporalité, à la fois dans la publication de Diagonal Cero et dans les livres de réécriture de l'artiste. Nous examinerons la projection de Diagonal Cero à l'Exposición Internacional de Novísima Poesía (l'Exposition Internationale de la Nouvelle Poésie), par le prisme de son montage. Ces descriptions nous permettront de considérer les productions comme partie prenante d'une conception du temps, intégrant la matérialité de la publication et l'esthétique de la participation.

Mots-Clé: Edgardo Antonio Vigo - Diagonal Cero - Poésie Visuelle - Temporalité.

Abstract: We propose to reflect on the temporality in Diagonal Cero publication (1962 to 1969), edited by the platense artist Edgardo Antonio Vigo. Work with the concept of montage as a key to temporality, both in terms of Diagonal Cero publication and in the artist's rewriting books. We propose to examine the projection of Diagonal Cero in the Exposición Internacional de Novísima Poesía, making reference to the assembly of the same. From these descriptions, we take the productions as part of a conception about time that includes the materiality of the publication and the aesthetics of participation.

Keywords: Edgardo Antonio Vigo - Diagonal Cero - Visual Poetry - Temporalities.

Resumo: Propomos refletir sobre a temporalidade na publicação Diagonal Cero (19621969), o editor foi o artista platense Edgardo Antonio Vigo. Trabalharemos com o conceito de montagem como uma chave para a temporalidade, tanto em termos da publicação Diagonal Cero quanto nos livros de reescrita do artista. Propomos examinar a projeção da Diagonal Cero na Exposición Internacional de Novísima Poesía, fazendo referência à montagem do mesmo. A partir dessas descrições, tomamos as produções como parte de uma concepção sobre o tempo que inclui a materialidade da publicação e a estética da participação.

Palavras chave: Edgardo Antonio Vigo - Diagonal Cero - Poesia Visual - Temporalidades.

[Las traducciones de los abstracts al francés, inglés y portugués fueron supervisadas por el autor de cada artículo] 